\title{
Mung Bean Protein Increases Plasma Cholesterol by up- regulation of Hepatic HMG-CoA Reductase, and CYP7A1 in mRNA Levels
}

\author{
Yang Yao, Yingying Zhu, Guixing Ren* \\ Institute of Crop Science, Chinese Academy of Agricultural Sciences, No. 80 South Xueyuan Road, Haidian District, Beijing, China \\ *Corresponding author: renguixing@caas.cn
}

Received September 04, 2014; Revised September 22, 2014; Accepted October 14, 2014

\begin{abstract}
Interest in mung bean as a cholesterol-lowering functional food is growing. The objective of this study was to investigate the effect of mung bean protein on the blood cholesterol level and gene expression of cholesterolregulating enzymes in Golden Syrian hamsters maintained on a $0.1 \%$ cholesterol diet. Results showed that mung bean protein (MBP) reduced plasma total cholesterol (TC), triacylglycerols and non-high-density lipoprotein cholesterol (non-HDL) concentrations as well as hepatic cholesterol concentrations after 6 week treatment. Realtime polymerase chain reaction analyses demonstrated mung bean protein could up-regulate the production of mRNA3-hydroxy-3-methyl glutaryl coenzyme A (HMG-CoA) reductase (HMGR) and cholesterol-7 $\alpha$-hydroxylase (CYP7A1) levels. The mechanisms underlying the cholesterol-lowering activity of MBP were mediated most likely by increasing the sterol excretion and decreasing the cholesterol absorption and synthesis. It is concluded that mung bean protein possesses the decreases plasma cholesterol activity and can be further explored as a functional food.
\end{abstract}

Keywords: Cholesterol, HMG-CoA reductase, Mung bean protein

Cite This Article: Yang Yao, Yingying Zhu, and Guixing Ren, "Mung Bean Protein Increases Plasma Cholesterol by up-regulation of Hepatic HMG-CoA Reductase, and CYP7A1 in mRNA Levels.” Journal of Food and Nutrition Research, vol. 2, no. 11 (2014): 770-775. doi: 10.12691/jfnr-2-11-2.

\section{Introduction}

Epidemiological studies show that diets based on the consumption of legumes can have a hypocholesterolaemic effect and reduce the risk of chronic diseases [1,2], especially for cardiovascular diseases. This function carries on by biologically active substances such as proteins, oils, dietary fibres, phytosterols and saponins [3]. Soya bean and its protein fractions 7S and 11S, are those that are most studied because of their effect in reducing total serum cholesterol and low-density lipoprotein cholesterol (LDL-C) through the modulation of genes related to the lipid metabolism [4,5]. Other seeds such as adzuki beans, peas, chick peas and lupin are also being investigated due to their chemical composition and great potential in the prevention of lipid disorders $[6,7,8,9]$. Mung bean has been shown to be hypocholesterolemic in animals $[10,11]$. However, no study has been undertaken to demonstrate the cholesterol-lowering effect of the mung bean protein (MBP) using hamsters, the best type of animal for use in experiments involving a lipid metabolism.

Blood total cholesterol (TC) and LDL-C correlate positively, whereas high-density lipoprotein cholesterol (HDL-C) correlates inversely with heart disease [12]. Although lipoprotein metabolism differs across species [13], cholesterol metabolism is governed at the transcriptional level by sterol regulatory element-binding protein 2 (SREBP) and liver X receptor-alpha (LXR $\alpha)$ in a coordinated manner [14]. The former regulates the transcription of 3-hydroxy-3-methyl glutaryl coenzyme A (HMG-CoA) reductase (HMGR) and low-density lipoprotein receptor (LDLR), with HMGR acting as a ratelimiting enzyme in cholesterol biosynthesis, whereas LDLR being responsible for the removal of LDL-C from the circulation. In contrast, the latter regulates the transcription of a gene encoding cholesterol-7 $\alpha$ hydroxylase (CYP7A1), a rate-limiting enzyme in conversion of cholesterol to bile acids in the liver and elimination in the bile fluid [14].

Despite some research on the link between mung bean and plasma lipoprotein profile, little is known about how MBP interacts with the genes expression involved in lipoprotein metabolism in vivo. The present study aimed to adopt hamsters as a model to (i) investigate the effect of dietary MBP on fecal excretion of individual neutral and acidic sterols; and (ii) characterize the interaction of mung bean with hepatic SREBP-2, LXRR, HMGR, LDLR, and CYP7A1 in mRNA levels.

\section{Materials and Methods}

\subsection{Protein Isolates Preparation}


MBP isolates was obtained from defatted mung bean flour by the method of $\mathrm{Li}$ et al. [15]. In brief, aqueous dispersion of the flour $(1: 6, \mathrm{w} / \mathrm{v})$ was kept overnight at $30^{\circ} \mathrm{C}$ in a water bath, then centrifuged at $3500 \mathrm{~g}$ for 20 min. The supernatant fraction was modified to $\mathrm{pH} 9.5$ with $1 \mathrm{M} \mathrm{NaOH}$ and magnetic stirring for $30 \mathrm{~min}$. The supernatant fraction was adjusted to $\mathrm{pH} 4.5$ with $1 \mathrm{M} \mathrm{HCl}$. Finally, the protein pellet was resuspended in water adjusted to $\mathrm{pH} 7.0$ with $1 \mathrm{M} \mathrm{NaOH}$, then centrifuged and lyophilized. Amino acid composition of defatted casein and MBP were listed in Table 1.

Table 1. Amino acid composition (\%) of defatted casein and mung bean protein isolate (MBP)

\begin{tabular}{ccc}
\hline & Casein & MBP \\
\hline Asp & $6.12 \pm 0.24$ & $9.07 \pm 0.02$ \\
Thr & $3.83 \pm 0.16$ & $2.56 \pm 0.07$ \\
Ser & $4.84 \pm 0.21$ & $4.02 \pm 0.03$ \\
Glu & $19.64 \pm 0.25$ & $15.46 \pm 0.04$ \\
Gly & $1.61 \pm 0.04$ & $2.79 \pm 0.02$ \\
Ala & $2.78 \pm 0.13$ & $3.33 \pm 0.03$ \\
Cys & $0.35 \pm 0.02$ & $0.41 \pm 0.01$ \\
Val & $6.03 \pm 0.12$ & $3.64 \pm 0.08$ \\
Met & $2.32 \pm 0.08$ & $0.09 \pm 0.01$ \\
Iie & $5.01 \pm 0.24$ & $3.24 \pm 0.12$ \\
Leu & $8.01 \pm 0.22$ & $6.02 \pm 0.23$ \\
Tyr & $4.62 \pm 0.19$ & $2.58 \pm 0.06$ \\
Phe & $4.48 \pm 0.24$ & $4.41 \pm 0.09$ \\
Lys & $7.01 \pm 0.42$ & $5.19 \pm 0.11$ \\
His & $2.54 \pm 0.13$ & $1.92 \pm 0.07$ \\
Arg & $3.32 \pm 0.21$ & $5.64 \pm 0.05$ \\
Pro & $9.26 \pm 0.67$ & $2.94 \pm 0.02$ \\
Arg/Lys & $0.47 \pm 0.01$ & $1.09 \pm 0.01$ \\
\hline Values were expressed as mean \pm SD. The measurement were repeated 3 \\
times.
\end{tabular}

\subsection{Diets}

Three diets were prepared according to previously described [16]. The control diet contained the following ingredients in proportion ( $\mathrm{g} / \mathrm{kg}$ diet): cornstarch, 508 casein, 242; lard, 50; sucrose, 119; mineral mix AIN-76, 40; vitamin mix AIN-76A, 20; DL-methionine, 1; cholesterol, 1. Two experimental diets were prepared by adding $1 \%(\mathrm{MBP}-1)$ and $2 \%$ (MBP-2) of MBP powder into the control diet, respectively. Powered diets were mixed with a gelatin solution (20 g/L) in a ratio of $200 \mathrm{~g}$ diet per liter of solution. Once the gelatin has set, the diets were cut into pieces of approximately $10 \mathrm{~g}$ cubes and stored frozen at $-20^{\circ} \mathrm{C}$.

\subsection{Animals}

Thirty (110-115 g, 2 months old) male adult Golden Syrian hamsters (Mesocricetus auratus) were obtained from the Department of Laboratory Animal Science, Peking University Health Science Center (Beijing, China). Hamsters were kept under standard conditions in an animal room with 12-h light/dark cycle (light 7:00-19:00) at a temperature $\left(22 \pm 2^{\circ} \mathrm{C}\right)$ and humidity $(60 \pm 5 \%)$.

Before the experiment, all the hamsters were acclimated on a $0.1 \%$ cholesterol diet (control diet) for 2 weeks. During the following 6 weeks, one group was continued to be fed the control diet and the two experimental groups were fed the experimental diets. Respective diets and water were available ad libitum, with any uneaten food being weighed and replaced with fresh food daily. Body weights were recorded and the fecal samples per cage were collected weekly. Blood was collected from the retro-orbital sinus into a heparinized capillary tube under light anesthetization, using a mixture of ketamine, xylazine and saline (v/v/v, 4:1:5), at the end of weeks 0,3 and 6 after food deprivation for $14 \mathrm{~h}$. After the blood was centrifuged at $1000 \times g$ for $10 \mathrm{~min}$, the plasma was collected and stored at $-20^{\circ} \mathrm{C}$ until analysis. After a 3-day recovery, all hamsters were sacrificed by carbon dioxide. The liver and heart were removed, washed in saline and weighed. The whole experiment was carried out complying with the European Community guidelines for the use of experimental animals and approved by the Peking University Committee on Animal Care and Use.

\subsection{Measurement of Plasma Lipoproteins}

Plasma TC, triacylglycerols (TG), HDL-C, LDL and very LDL were quantified using the enzymatic kits from Nanjing Jiancheng Bioengineering Institute (Nanjing, China). Non-HDL-C was measured by deducting HDL-C from TC [17].

\subsection{Determination of Organ Cholesterol}

Cholesterol in organs was determined using a method as described previously [18]. Briefly, $1 \mathrm{mg}$ stigmastanol as an internal standard was added into $300 \mathrm{mg}$ of organ sample. Methanol-chloroform mixture (2:1, v/v) was used to extract total lipids. The chloroform-methanol layer was saved and evaporated to dryness under a gentle stream of nitrogen gas. Lipids were then mildly saponified and the cholesterol was converted into its trimethylsilyl-ether (TMS) derivative by a commercial TMS (Sigma-Sil-A, Sigma, St. Louis, MO, USA). The analysis of cholesterol TMS-ether derivative was performed in a fused silica capillary column (SAC-5, $30 \mathrm{~m} \times 0.25 \mathrm{~mm}$, i.d, Supelco, Bellefonte, PA, USA) GC-MS (Shimadzu QP2010, Tokyo, Japan) equipped with a flame ionization detector.

\subsection{Quantification of Fecal Neutral and Acidic Sterols}

Individual fecal neutral and acidic sterols were quantified as previously described [19]. In brief, stigmasterol was added to the sample as an internal standard for quantification of neutral sterols, whereas hyodeoxycholic acid was added as an internal standard for quantification of acidic sterols. The total neutral sterols were extracted using cyclohexane and were converted into their TMS derivatives for gas chromatography (GC) analysis. The acidic sterols in the remaining aqueous layer were saponified and extracted into diethyl ether. The acidic sterols were also converted to their TMS derivatives for GC analysis. Both the analyses of individual neutral and acidic sterol TMS derivatives were performed in a fused silica capillary column (SAC-5, $30 \mathrm{~m} \times 0.25 \mathrm{~mm}$, i.d, Supelco, Bellefonte, PA, USA) utilizing a GC-MS (Shimadzu QP2010, Tokyo, Japan) equipped with a flame ionization detector.

\subsection{Real Time PCR Analyses}

Real-time PCR analysis of mRNA was conducted as previously described [17]. Briefly, liver mRNA was extracted and isolated using Tizol reagent (Invitrogen, Carslbad, CA, USA). Total RNA was converted to cDNA 
using a high capacity cDNA reverse transcription kit (Applied Biosystems, Foster City, CA, USA). Reverse transcription was carried out in a thermocycler (Gene Amp PCR system 9700, Applied Biosystems, Foster City, CA, USA), with program set as initiation for $10 \mathrm{~min}$ at $25^{\circ} \mathrm{C}$, followed by incubation at $37^{\circ} \mathrm{C}$ for $120 \mathrm{~min}$ and at $85^{\circ} \mathrm{C}$ for an additional $5 \mathrm{~min}$. The cDNA synthesized was stored at $-20^{\circ} \mathrm{C}$. Real-time PCR analysis was carried out on a Fast Realtime PCR System 7900 HT (Applied Biosystems, Foster City, CA, USA). Primers and TaqMan probes were used for real-time PCR analysis of liver glyceraldehyde-phosphate dehydrogenase (GAPDH), CYP7A1, HMG-CoA reductase, LDL-R, SREBP-2 and LXR $\alpha$ (Table 2). The reaction mixture was subjected to thermal cycling under the following conditions: heating to $95^{\circ} \mathrm{C}$ in $20 \mathrm{~s}$, followed by 35 cycles at $95^{\circ} \mathrm{C}$ for $3 \mathrm{~s}$ and $60^{\circ} \mathrm{C}$ for 30 s. Data were analyzed using Sequence Detection Software version 2.3 (Applied Biosystems, Foster City, CA, USA). Gene expressions were calculated on the basis of the comparative threshold cycle $\left(C_{\mathrm{T}}\right)$ method (Applied Biosystems, Foster City, CA, USA).

Table 2. Real-Time primers used to amplify mRNA by real-time PCR

\begin{tabular}{ccc} 
& Table 2 . Real-Time primers used to amplify mRNA by real-time PCR & Reverse primer 5' $\rightarrow 3^{\prime}$ \\
\hline Gene & Forward primer $5{ }^{\prime} \rightarrow 3^{\prime}$ & CCAGTGAGCTTCCCGTTCA \\
GAPDH & GAACATCATCCCTGCATCCA & ACAGCCCAGGTATGGAATCAAV \\
HMG-CoA R & GGTAGTGTGCTGTTGTATATGGGTTA & GCCATAGTCACATGAAGCTTCTGTA \\
LDL-R & CGAAGGGTTTGCAGTGATAAAGGA & ACAGCCACCATTGTTGTCCA \\
LXR- $\alpha$ & GCCGGGACTGGTCAG ATG & CGGGCTTCCACTACAATGTT \\
SREBP-2 & TCAGGCGGATCTGTTCTTCT & TGTAATCAATGGCCTTCCTCAGAAC \\
\hline
\end{tabular}

Abbreviation: GAPDH, glyceraldehyde-phosphate dehydrogenase; HMG-CoA R, mRNA3-hydroxy-3-methyl glutaryl coenzyme A reductase; LDL-R, low-density lipoprotein receptor; SREBP-2, sterol regulatory element-binding protein 2; LXR- $\alpha$, liver X receptor-alpha; CYP7A1, cholesterol-7 $\alpha$ hydroxylase.

\subsection{Statistics}

Data was expressed as Mean \pm SD. The group means were statistically analyzed using one-way analysis of variance (ANOVA) and post hoc LSD test (SPSS, Chicago, IL, USA). Significance was defined as $p$-value less than 0.05 .

\section{Results}

\subsection{Food Intake, Body and Organ Weight}

There was no significant difference in the final body weight between the two groups. MBP did not affect the weights of kidney, heart, liver and adipose tissues (epididymal and perirenal pads) compared with that in the control. Similarly, there were no significant differences in food intake between the control and the experimental diet group.

\subsection{Plasma TC, HDL-C, TG and non-HDL- C/HDL-C in Hamsters}

Three groups of hamsters had similar levels of plasma TC, TG and HDL-C at the beginning of the experiment (week 0). At the end of week 3, plasma TC, non-HDL-C, non-HDL-C: HDL-C and TC: HDL-C were dosedependently decreased (Table 3) with the increasing MBP level. When the experiment reached the end of week 6 , the MBP-induced reduction in plasma TC, TG, non-HDL-C, non-HDL-C: HDL-C and TC: HDL-C became significant compared with those in the control (Table 3). MBP levels had no effect on plasma TG at the end of week 3. However, plasma TG demonstrated a dose-dependent decrease with the increasing MBP at the end of week 6 (Table 3).

Table 3. Changes in hepatic cholesterol and plasma TC, TG, HDL-C, non-HDL-C, and TC/HDL-C ratio in hamsters fed the control and two experimental diets supplemented with MBP-1 and MBP-2

\begin{tabular}{|c|c|c|c|}
\hline & Control & MBP-1 & MBP-2 \\
\hline \multicolumn{4}{|l|}{ week 0} \\
\hline TC (mg/dL) & $208.3 \pm 24.5$ & $206.4 \pm 22.1$ & $205.9 \pm 24.8$ \\
\hline TG (mg/dL) & $133.6 \pm 37.8$ & $141.3 \pm 20.3$ & $138.9 \pm 24.7$ \\
\hline HDL-C (mg/dL) & $95.3 \pm 16.3$ & $93.4 \pm 14.4$ & $94.7 \pm 15.9$ \\
\hline non- HDL-C (mg/dL) & $105.4 \pm 18.1$ & $112.8 \pm 14.6$ & $111.4 \pm 12.7$ \\
\hline non- HDL-C/ HDL-C & $1.2 \pm 0.2$ & $1.2 \pm 0.2$ & $1.2 \pm 0.3$ \\
\hline $\begin{array}{c}\text { TC/ HDL-C } \\
\text { week } 3\end{array}$ & $2.2 \pm 0.2$ & $2.2 \pm 0.3$ & $2.2 \pm 0.4$ \\
\hline $\mathrm{TC}(\mathrm{mg} / \mathrm{dL})$ & $237.5 \pm 14.1^{\mathrm{a}}$ & $228.1 \pm 14.8^{\mathrm{ab}}$ & $205.7 \pm 16.9^{b}$ \\
\hline TG (mg/dL) & $154.4 \pm 28.5$ & $153.9 \pm 28.4$ & $151.1 \pm 20.4$ \\
\hline HDL-C (mg/dL) & $94.7 \pm 14.5$ & $97.2 \pm 13.6$ & $95.7 \pm 15.1$ \\
\hline non- HDL-C (mg/dL) & $139.4 \pm 12.7^{\mathrm{a}}$ & $129.6 \pm 15.4^{\mathrm{ab}}$ & $106.9 \pm 11.7^{b}$ \\
\hline non- HDL-C/ HDL-C & $1.5 \pm 0.2^{\mathrm{a}}$ & $1.3 \pm 0.2^{b}$ & $1.1 \pm 0.2^{b}$ \\
\hline $\begin{array}{l}\text { TC/ HDL-C } \\
\text { week } 6\end{array}$ & $2.5 \pm 0.2^{\mathrm{a}}$ & $2.4 \pm 0.3^{b}$ & $2.2 \pm 0.2^{b}$ \\
\hline TC (mg/dL) & $251.3 \pm 26.7^{\mathrm{a}}$ & $221.3 \pm 14.6^{\mathrm{a}}$ & $208.1 \pm 13.5^{b}$ \\
\hline TG (mg/dL) & $197.3 \pm 19.5^{\mathrm{a}}$ & $190.1 \pm 15.7^{b}$ & $186.6 \pm 14.6^{b}$ \\
\hline HDL-C (mg/dL) & $103.3 \pm 14.5$ & $105.1 \pm 12.1$ & $106.3 \pm 12.4$ \\
\hline non- HDL-C (mg/dL) & $137.1 \pm 22.4^{\mathrm{a}}$ & $117.3 \pm 14.6^{\mathrm{b}}$ & $92.7 \pm 10.8^{b}$ \\
\hline non- HDL-C/ HDL-C & $1.3 \pm 0.2^{\mathrm{a}}$ & $1.1 \pm 0.2^{\mathrm{ab}}$ & $0.9 \pm 0.2^{\mathrm{b}}$ \\
\hline TC/ HDL-C & $2.4 \pm 0.2^{a}$ & $2.1 \pm 0.3^{b}$ & $2.0 \pm 0.3^{b}$ \\
\hline Liver cholesterol (mg/g) & $62.6 \pm 7.4^{\mathrm{a}}$ & $57.2 \pm 6.2^{b}$ & $54.5 \pm 6.2^{b}$ \\
\hline
\end{tabular}

Values were expressed as mean \pm SD $(n=10)$. Means at the same row differed significantly at $p<0.05(\mathrm{a}, \mathrm{b})$.

Abbreviation: TC, total cholesterol; TG, triacylglycerols; HDL-C, high-density lipoprotein cholesterol; non-HDL-C, non-HDL cholesterol; MBP-1, diets were prepared by adding $1 \%$ of MBP powder; MBP-2, diets were prepared by adding $2 \%$ of MBP powder. 


\subsection{Liver Cholesterol}

Hepatic cholesterol demonstrated a dose-dependent decrease pattern with the increasing MBP contents (Table 3). Compared with that in control group, liver cholesterol was reduced by $8.6 \%$ in MBP-1, and $12.9 \%$ in MBP-2 group.

\subsection{Fecal Total Sterols Excretion and Apparent Cholesterol}

With regard to the fecal individual acidic sterols, the two experimental groups had greater excretion of lithocholic acid, chenodeoxycholic acid, cholic acid and ursocholic acid compared with the control hamsters (Table
4). Greater excretion of fecal coprostanol was observed in the MBP group compared with the control hamster (Table 4). Compared with those in the control group, total fecal neutral sterols were increased in the MBP-1 and MBP-2 groups. It was apparent that the total sterol excretion (sum of neutral and acidic) was increased in the experimental groups compared with the control hamsters.

Total intake of cholesterol was compared with the excretion of neutral and acidic sterols (Table 4). Cholesterol retention was calculated by difference between the intake and excretion of both neutral and acidic sterols. The apparent cholesterol absorption (cholesterol retention/cholesterol intake) demonstrated a dose-dependent decrease with the increasing MBP levels.

Table 4. Fecal excretion of neutral and acidic sterol (milligrams per day) in hamsters fed the control and two experimental diets supplemented with MBP-1 and MBP-2

\begin{tabular}{|c|c|c|c|}
\hline Diet group & Control & MBP-1 & MBP-2 \\
\hline \multicolumn{4}{|l|}{ Acidic sterols } \\
\hline Lithocholic acid & $0.75 \pm 0.27^{b}$ & $0.97 \pm 0.31^{\mathrm{a}}$ & $1.21 \pm 0.32^{\mathrm{a}}$ \\
\hline Deoxycholic acid & $0.11 \pm 0.03$ & $0.13 \pm 0.05$ & $0.15 \pm 0.04$ \\
\hline Chenodeoxycholic acid & $0.23 \pm 0.14^{\mathrm{b}}$ & $0.25 \pm 0.19^{\mathrm{ab}}$ & $0.34 \pm 0.07^{\mathrm{a}}$ \\
\hline Cholic acid & $0.10 \pm 0.06^{b}$ & $0.19 \pm 0.05^{\mathrm{a}}$ & $0.22 \pm 0.06^{\mathrm{a}}$ \\
\hline Ursocholic acid & $0.05 \pm 0.04^{b}$ & $0.07 \pm 0.04^{\mathrm{ab}}$ & $0.08 \pm 0.04^{\mathrm{a}}$ \\
\hline Total acidic sterol & $1.25 \pm 0.51^{b}$ & $1.60 \pm 0.56^{\mathrm{a}}$ & $2.01 \pm 0.55^{\mathrm{a}}$ \\
\hline \multicolumn{4}{|l|}{ Neutral sterols } \\
\hline Coprostanone & $0.04 \pm 0.02$ & $0.04 \pm 0.01$ & $0.04 \pm 0.02$ \\
\hline Cholesterol & $0.36 \pm 0.15$ & $0.35 \pm 0.18$ & $0.40 \pm 0.19$ \\
\hline Dihydrocholesterol & $0.18 \pm 0.03$ & $0.21 \pm 0.04$ & $0.22 \pm 0.05$ \\
\hline Campesterol & $0.06 \pm 0.02$ & $0.07 \pm 0.03$ & $0.07 \pm 0.02$ \\
\hline Total neutral sterol & $1.45 \pm 0.33^{\mathrm{b}}$ & $1.94 \pm 0.42^{\mathrm{a}}$ & $2.06 \pm 0.38^{\mathrm{a}}$ \\
\hline Cholesterol intake & $12.31 \pm 0.95$ & $12.55 \pm 0.65$ & $12.59 \pm 0.49$ \\
\hline Total sterol excretion & $2.72 \pm 0.92^{b}$ & $3.51 \pm 1.03^{\mathrm{a}}$ & $3.98 \pm 1.18^{\mathrm{a}}$ \\
\hline Apparent cholesterol absorption & $62.32 \pm 3.41^{\mathrm{a}}$ & $56.34 \pm 3.54^{\mathrm{b}}$ & $51.57 \pm 3.88^{b}$ \\
\hline
\end{tabular}

Values were expressed as mean \pm SD $(n=10)$. Means at the same row differ significantly at $p<0.05(\mathrm{a}, \mathrm{b})$

Abbreviation: MBP-1, diets were prepared by adding 1\% of MBP powder; MBP-2, diets were prepared by adding $2 \%$ of MBP powder.

3.5. mRNA Analysis of SREBP-2, HMG-CoA R, LDLR, LXRa, and CYP7A1
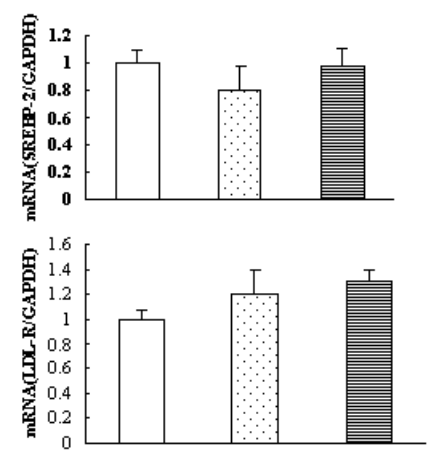

The RT-PCR (he production of mRNA HMGR and CYP7A1 levels, but no significant effect on hepatic SREBP-2, LDL-R and LXR $\alpha$ in hamsters (Figure 1).
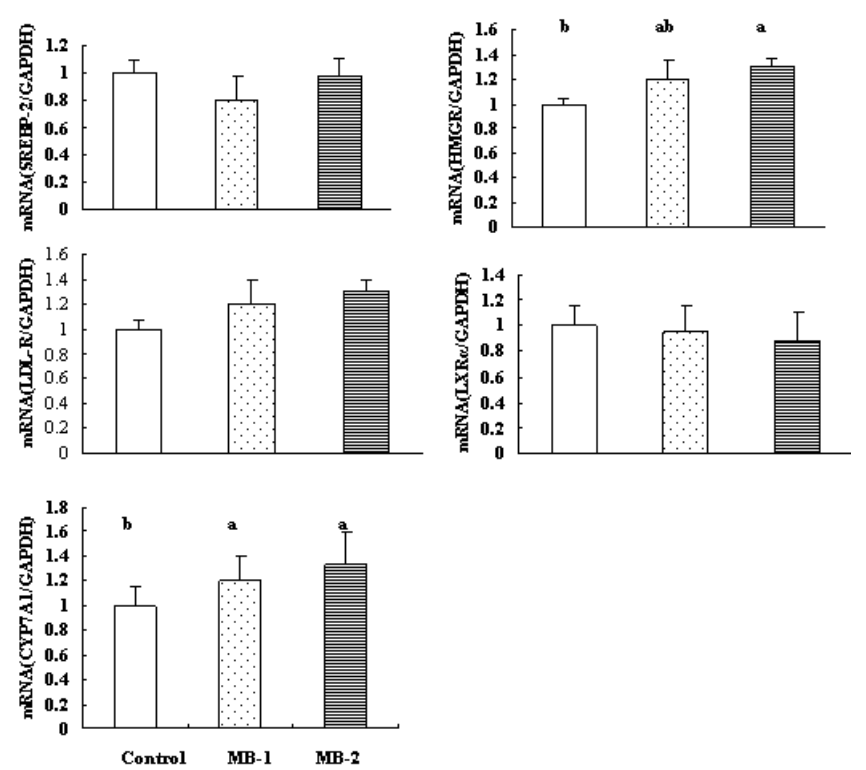

Figure 1. The mRNA of hepatic SREBP-2, HMG-CoA-R, LDL-R, liver X receptor (LXR) and cholesterol- 7 $\alpha$-hydroxylase (CYP7A1) in hamsters fed the control diet, and two experimental diets supplemented with containing 1\% mung bean (MB-1) and 2\% mung bean (MB-2) for the 6 weeks. Each group contained 10 hamsters. MBP could up-regulate the production of mRNA HMGR and CYP7A1 levels, but no significant effect on hepatic SREBP-2, LDL-R and LXR $\alpha$ in hamsters 


\section{Discussion}

Epidemiological studies revealed significant inverse relationships between legume intake and the risk of coronary heart disease and cardiovascular disease. Rats and hamsters are commonly used animal models to test the efficacy of these functional foods in lowering blood cholesterol levels. However, like humans, hamsters had serum LDL-C and HDL-C increased proportionally, whereas rats had only LDL-C raised with HDL-C being decreased in response to the increasing cholesterol in diet. Moreover, serum HDL-C in hamsters accounted for $40 \%$ serum TC [20], which is closer to that in humans, whereas in rats, it only accounted for $10 \%$ TC when dietary cholesterol was increased from 0 to $0.9 \%$ in diets. In additional, serum TG level was raised in a dose-dependent manner in hamsters, whereas it was decreased in rats when cholesterol in diet was increased from 0 to $0.9 \%$ [21]. So hamsters would be a better model than rats to study the cholesterol-lowering activity of nutraceuticals and functional foods.

The present study found that MBP dose-dependently reduced plasma TC, TG, non-HDL-C, non-HDL-C/HDL$\mathrm{C}$ and TC/HDL-C levels in hamsters fed a highcholesterol diet. Results suggest that MBP supplementation beneficially models the circulating lipid profile in a dose-dependent manner. This result was in agreement with that of earlier observation that the supplementation of mung bean suppressed the increase in the TC and TG levels in the serum of diabetic mice and ethanol-mediated liver damaged mice [10,11,22]. Studies on mixed legumes suggested that their consumption lowers LDL-cholesterol by partially interrupting the enterohepatic circulation of bile acids and increases cholesterol saturation of bile by increasing the secretion of cholesterol [23]. Consumption of pinto beans showed decreases in both LDL- and HDL cholesterol [24]. Dietary amino acid composition was reported to have some effect on the plasma cholesterol level. Vahouny et al [25] reported that a high Arg/Lys ratio in soybean protein was responsible for its cholesterol-lowering effect due to decreased intestinal lipid absorption.

The present study is the first of its kind to study the effect of MBP on cholesterol balance. It is known that excessive cholesterol is mainly eliminated by mammals in forms of fecal bile neutral and bile acids. This will allow us to obtain information on the quantity of cholesterol intake, cholesterol elimination (sum of both fecal neutral and acidic sterols), and the net body accumulation of cholesterol relative to dietary cholesterol [16]. The present study found that the net cholesterol retention or the apparent cholesterol absorption was the highest in the control followed by MBP-1, and MBP-2 groups in a decreasing order (Table 4), suggesting that MBP shift the cholesterol balance in a way towards greater cholesterol elimination. MBP also increased fecal bile acids output (Table 4). This was partially mediated by up-regulation of CYP7A1 in both transcriptional and translational levels. Similar results were observed by Kahlon and Smith who demonstrated that mung bean binding human bile at a duodenal physiological $\mathrm{pH}$ of 6.3 in vitro [26]. Binding of bile acids and increasing fecal excretion has been hypothesized as a major mechanism by which food fractions lower cholesterol [27]. By binding bile acids, food fractions prevent their reabsorption and stimulate plasma and liver cholesterol conversion to additional bile acids $[26,28]$. The observed increase in the mRNA HMGCoAR could be explained by the decrease in hepatic cholesterol concentration in MBP group. The HMGCoAR is sensitive to the cholesterol concentration in the liver and become up-regulated if the liver cholesterol is reduced.

In summary, we studied the effect of MBP on the serum lipoprotein profile, finding that MBP was hypocholesterolemic. It is evidence that supplementation of MBP into diet led to greater excretion of fecal neutral sterols. It was therefore concluded that the cholesterollowering activity of MBP was associated with inhibition of cholesterol absorption.

\section{Acknowledgements}

This project was supported by the Program for HongKong, Macao and Taiwan Science \& Technology Cooperation Program of China (2013DFH30050), Special Fund for Agroscientific Research in the Public Interest (201403063), earmarked fund for China Agriculture Research System Modern Agro-industry Technology (CYTX-018) and Sci \& Tech Innovation Program of CAAS.

\section{Statement of Competing Interests}

The authors have no competing interests.

\section{List of Abbreviations}

MBP, mung bean protein; non-HDL, non-high-density lipoprotein cholesterol; HMG-CoA, mRNA3-hydroxy-3methyl glutaryl coenzyme A; HMGR, HMG-CoA reductase; LDLR, low-density lipoprotein receptor; LDLC, serum low-density lipoprotein cholesterol; HDL-C, high-density lipoprotein cholesterol; SREBP, sterol regulatory element-binding protein 2; GAPDH, glyceraldehyde-phosphate dehydrogenase ; LXR $\alpha$, liver X receptor-alpha; CYP7A1, cholesterol-7 $\alpha$-hydroxylase; MBP-1, diets were prepared by adding $1 \%$ of MBP powder; MBP-2, diets were prepared by adding $2 \%$ of MBP powder; TG, triacylglycerols; TMS, trimethylsilylether; GC, gas chromatography.

\section{References}

[1] Anderson, W. and Major, A. M., "Pulses and lipaemia, short and long term effect. potential in prevention on cardiovascular disease,” British Journal of Nutrition, 88 (3): 263-271. 2002.

[2] Craig, W. J., "Phytochemicals. Guardians of our health,” Journal of the American Dietetic Association, 97: s199-s204. 1997.

[3] Sirtori, C. R., Galli, C., Anderson, J. W. and Arnoldi, A., "Nutritional and nutraceutical approaches to dyslipidemia and atherosclerosis prevention Focus on dietary proteins," Atherosclerosis, 23 (1): 8-17. 2009.

[4] Anderson, J. W., Johnstone, B. M. and Cook-Newell, M. E., "Meta-analysis of the effects of soy protein intake on serum lipid," The New England Journal of Medicine, 333: 276-282. 1995. 
[5] Reynolds, K., Chin, A., Lees, K. A., Nguyen, A., Bujnowsk,i D. and He, J. A., "Meta analysis of the effect of soy protein supplementation on serum lipids," American Journal of Cardiology, 98: 633-640. 2006.

[6] Nishi S., Saito Y., Souma C., Kato J., Koaze H., Hironaka, K. and Kojima, M., "Suppression of serum cholesterol levels in mice by adzuki bean polyphenols," Food Science and Technology Research, 14 (2): 217- 220. 2008.

[7] Parolini, C., Manzini, S., Busnelli, M., Rigamonti, E., Marchesi, M., Diani, E., Sirtori, C. R. and Chiesa, G.., "Effect of the combinations between pea proteins and soluble fibres on cholesterolaemia and cholesterol metabolism in rats," British Journal of Nutrition, 110: 1394-1401. 2013.

[8] Algam, T. A., Atti, K. A. A., Dousa, B. M. and Elawad, S. M., "Elseed AMF., Effect of dietary raw chick pea (Cicer arietinum L.) seeds on broiler performance and blood constituents," International Journal of Poultry Science, 11 (4): 294-297. 2012.

[9] Sirtori, C. R., Lovati, M. R., Manzoni, C., Castiglioni, S., Duranti, M., Magni, C., Morandi, S., D'Agostina, A. and Arnoldi, A., "Proteins of white lupin seed, a naturally isoflavone-poor legume, reduce cholesterolemia in rats and increase LDL-receptor activity in hepG2 cells,” Journal of Nutrition, 134: 18-23. 2004.

[10] Ali, N. M., Yusof, H. M., Long, K., Yeap, S. K., Ho, W. Y., Beh, B. K., Koh, S. P., Abdullah, M. P. and Alitheen, N. B., "Antioxidant and hepatoprotective effect of aqueous extract of germinated and fermented mung bean on ethanol-mediated liver damage,” BioMed Research International.

[11] Yeap, S. K., Ali, N. M., Yusof, H. M., Alitheen, N. B., Beh, B. K., Koh, S. P. and Long, K., "Antihyperglycemic effects of fermented and nonfermented mung bean extracts on alloxan-induced-diabetic mice,” BioMed Research International.

[12] Karnik, R., "The value of lipid lowering in patients with coronary heart disease,” Journal of Clinical and Basic Cardiology, 4 (1). 31-34. 2001.

[13] Lin, Y., Chou, C., Yang, D., Chen, J., Tzang, B. and Chen, Y., "Hypolipidemic and antioxidative effects of noni (morinda citrifolia L.) juice on high- fat/cholesterol-dietary hamsters,” Plant Foods for Human Nutrition, 67: 294-302. 2012.

[14] Lee, J, Y., Mitmesser, S. H. and Carr, T. P., "Regulation of cellular cholesterol,” In Molecular Nutrition. CABI Publishing. London, U.K, pp 309-320. 2002.

[15] Li, G. H., Le, G. W., Liu, H., and Shi, Y. H. "Mung-bean protein hydrolysates obtained with alcalase exhibit angiotensin Iconverting enzyme inhibitory activity," Food Science and Technology International, 11 (4). 281-287.2005.

[16] Lam, C. K., Zhang, Z. S., Yu, H., Tsang, S. Y., Huang, Y. and Chen, Z. Y., "Apple polyphenols inhibit plasma CETP activity and reduce the ratio of non-HDL to HDL," Molecular Nutrition \& Food Research, 52: 950-958. 2008.

[17] Chen, J. N., Jiang, Y., Ma, K.Y., Chen, F. and Chen, Z. Y., "Microalga Decreases Plasma Cholesterol by Down-regulation of
Intestinal NPC1L1, Hepatic LDL Receptor, and HMG-CoA Reductase,” Journal of Agricultural and Food Chemistry, 59: 6790-6797. 2010.

[18] Chan, P. T., Fong, W. P., Cheung, Y. L., Huang, Y., Ho, W. K. and Chen, Z. Y., "Jasmine green tea epicatechins are hypolipidemic in hamsters fed a high fat diet,” Journal of Nutrition, 129: 1094-1101. 1999.

[19] Jiao, R., Zhang, Z., Yu, H., Huang, Y. and Chen, Z. Y., "Hypocholesterolemic activity of grape seed proanthocyanidin is mediated by enhancement of bile acid excretion and up- regulation of CYP7A1,” Journal of Nutritional Biochemistry, 21: 1134-1139. 2010.

[20] Lin, D. S. and Connor, W. E., "The long term effects of dietary cholesterol upon the plasma lipids, lipoproteins, cholesterol abssorption, and the sterol balance in man: The demonstration of feedback inhibition of cholesterol biosynthesis and increased bile acid excretion, ” Journal of Lipid Reseach, 21: 1042-1052. 1980.

[21] Zhang, Z. S., Wang, H., Jiao, R., Peng, C., Wong,Y, M.,Yu, H., Yeung, V. S. Y., Huang, Y. and Chen, ZY., "Choosing hamsters but not rats as a model for studying plasma cholesterol-lowering activity of functional foods” Molecular Nutrition Food Reserch, 53: 921-930, 2009.

[22] Yao, Y., Ren, G. X., Wang, J. S., Chen, F. and Wang, M. F., "Antidiatbetic activity of mung bean extracts in diabetic KK- Ay mice,” Journal of Agricultural and Food Chemistry, 56: 88698873. 2008.

[23] Duane, W. C., "Effects of legume consumption on serum cholesterol, biliary lipids, and sterol metabolism in humans," Journal of Lipid Research, 38: 1120-1128. 1997.

[24] Finley, J. W., Burrell, J. B. and Reeves, P. G., "Pinto bean consumption changes SCFA profiles in fecal fermentation, bacterial populations of the lower bowel, and lipid profiles in blood of humans,” Journal of Nutrition, 135: 2391-2398. 2007.

[25] Vahouny, G..V., Adamson, I., and Chalcarz, W., Satchihanandam, S., Muesing, R., Klurfeld, D. M., Tepper, S. A., Sanghvi, A. and Kritchevsky, D., "Effects of casein and soy protein on hepatic and serum lipids and lipoprotein lipid distributions in the rat," Atherosclerosis, 56: 127-137. 1985.

[26] Kahlon, T. S. and Smith, G. E., "In vitro binding of bile acids by okra, beets, asparagus, eggplant, turnips, green beans, carrots, and cauliflower,” Food Chemistry, 103: 676-680. 2007.

[27] Lund, E. K., Gee, J. M., Brown, J. C., Wood, P. J. and Johnson, I. T., "Effect of oat gum on the physical properties of the gastrointestinal contents and on the uptake of D-galactose and cholesterol by rat small intestine in vitro," British Journal of Nutrition, 62: 91-101. 1989.

[28] Tiengo, A., Motta, E. M. and Netto, F. M., "Chemical composition and bile acid binding activity of products obtained from amaranth (amaranthus cruentus) seeds," Plant Foods for Human Nutrition, 66: 370-375. 2011. 